\title{
Currículo, reformas e a questão da formação humana: uma reflexão a partir da Teoria Crítica da Sociedade
}

\author{
Monica Ribeiro da Silva*
}

Nos casos em que a cultura foi entendida

como conformar-se à vida real,

ela destacou unilateralmente o momento da adaptação, e impediu, assim, que os homens se educassem uns aos outros.

Theodor Adorno

\begin{abstract}
RESUMO
Reflexão sobre o currículo como prática escolar que tem consubstanciado processos de falsa formação cultural ao incorporar a racionalidade produzida por práticas culturais guiadas por uma lógica instrumental e mercantilizada. A importância do assunto mostra-se na centralidade que tem ocupado o currículo, o que se evidencia nas reformas educacionais da atualidade, brevemente discutidas. A análise toma por referência a Teoria Crítica da Sociedade conforme os escritos de T. Adorno, M. Horkheimer e H. Marcuse.

Palavras-chave: currículo, reformas educacionais, Teoria Crítica da Sociedade.
\end{abstract}

\footnotetext{
ABSTRACT

Reflexion of school practices curriculum that consolidate a false cultural development process, when incorporating the rationality that comes from cultural practices guided by instrumental and mercantile logic. The

* Professora do Departamento de Planejamento e Administração Escolar da UFPR e Doutoranda em Educação pelo Programa de Estudos Pós-Graduados em Educação, História, Política e Sociedade da PUC-SP. rsmonica@uol.com.br
} 
importance of the subject is shown in the centrality that it has been occupyng the curriculum, which is evident in the recent educacional reforms, briefly discussed. The analysis uses the Society's Critical Theory for reference, as as written by T. Adorno, M. Horkheimer and H. Marcuse. Key-words: curriculum, educational reforms, Society's Critical Theory.

O significado do termo cultura tem se mostrado relevante diante da necessidade de compreensão dos processos formativos escolares e não escolares. ADORNO (1996), em "Teoria da Semicultura", ${ }^{1}$ oferece uma possibilidade de análise, ao apontar as causas por meio das quais a formação humana tem se convertido, na sociedade burguesa, em falsa formação cultural. A compreensão da cultura enquanto práxis, em oposição ao sentido de "cultura do espírito", o significado de cultura como conjunto de práticas que conferem determinados significados a indivíduos e grupos, insere o propósito da formação humana nos contextos de apropriação e subjetivação do mundo, que, a princípio, conduziria os homens a um processo de identificação e, ao mesmo tempo, de diferenciação sociais. No entanto, o caráter instrumental que a cultura tem adquirido em nossa sociedade, tem imposto limite às condições em que se dá a formação humana. Nesse sentido, a formação cultural tem se convertido muito mais em pseudoformação. O enquadramento racional das categorias que têm estado na base da formação burguesa, o acesso a formas de pensar e a práticas de conhecer marcadas pela "razão esclarecida" (ADORNO, 1985) tem congelado as possibilidades de emancipação do homem e imposto limites à possibilidade de formação capaz de levá-lo à autoreflexão crítica, isto é, à consciência da pseudoformação, única possibilidade de sobrevivência que restaria à cultura. (ADORNO, 1996, p. 410)

A formação burguesa tem se constituído de uma socialização sustentada em processos de adaptação, dos mais simples e visíveis aos mais elaborados e objetivados em práticas formais, como é o caso da escola, que se institui por um certo tipo de organização do trabalho que, ao reproduzir sem crítica a racionalidade instrumental, estabelece na educação seu caráter conservador e conformador.

A escola burguesa, que tem suas origens vinculadas às transformações fundantes dessa sociedade, está marcada pelas funções sociais que tem cumpri-

1 Mantém-se, neste trabalho, a tradução tal qual se encontra na referência bibliográfica utilizada. Quanto ao termo "semiformação", optou-se por substitui-lo por "pseudoformação", por se compreender que este último corresponde melhor ao sentido dado por ADORNO (1996). 
do desde então, dentre elas a de inserir todos os indivíduos nas presentes relações sociais e de produção, a de produzir "consumidores", por meio da disseminação de comportamentos, condutas, hábitos, valores, idéias e ideologias, bem como tem contribuído para contextos sociais que têm favorecido a reprodução capitalista. (DALE, 1988)

Em nossa sociedade, marcada por práticas sociais excludentes e por uma educação escolar tradicionalmente assentada na dominação e no controle do indivíduo, qualquer intenção de formação humana voltada para a emancipação deveria tomar como fim uma formação cultural voltada para a "autoreflexão crítica". Isso corresponde a pensar na possibilidade de uma formação que leve em consideração a capacidade do indivíduo tornar-se autônomo - intelectual e moralmente -, ao mesmo tempo em que, ao ser capaz de interpretar as condições histórico-culturais da sociedade em que vive, saiba identificar os mecanismos que têm confinado o homem à eminência da barbárie e lutar contra eles.

O modo como a instituição escolar tem se organizado tem reforçado mecanismos geradores de adaptação e dominação. A razão que demarca objetivos, metas e finalidades, impõe, a priori, os desígnios de formação individual. A reprodução memorizada dos bens culturais submete o comportamento aos modelos facilmente consumíveis da indústria cultural e remete, sem culpa, à aceitabilidade da padronização e da massificação. As formas de pensar geradas pelo modo como se organizam os saberes escolares, sua lógica disciplinar e prescritiva, moldada pelo esclarecimento fundante das modernas ciências naturais, sedimentam modos de aprender pela repetição, memorização e reprodução das idéias alheias. O objeto da aprendizagem, um conhecimento fragmentado, cindido, mas legitimado pelo status de ciência, tem conduzido a formalidade das práticas escolares e curriculares a procedimentos que parecem ter sua lógica submetida exclusivamente a eles mesmos.

Os métodos de ensino encerram em si a mesma lógica instrumental da busca de um método único capaz de ensinar tudo a todos, passamos pelas pedagogias ativas centradas nos ritmos individuais e chegamos à conversibilidade do conhecimento em técnica - e têm consubstanciado um emaranhado de tentativas de formação que, no limite, circunscrevem processos de pseudoformação.

As práticas escolares e curriculares têm se cercado ainda de modelos de disciplinamento do corpo e da mente que simbolizam e materializam modos de conduta que têm impossibilitado a autodeterminação da consciência. Dos meios legitimados e institucionalizados, a avaliação da aprendizagem escolar é o mais expressivo mecanismo de controle que se imprime aos alunos e os 
submete diante das ameaças de reprovação e exposição moral. Essa forma de organização não é outra coisa senão aquilo que ADORNO (1996) chamou de sedimentação de um espírito objetivo negativo e que tem convertido a formação cultural em pseudoformação.

O currículo escolar sempre esteve, de algum modo, vinculado a procedimentos de seleção da cultura. A concepção originária, no contexto da moderna escola burguesa, tem sido reconhecida como a vertente tradicionalhumanista e se fundamenta em uma concepção de cultura como algo fixo e estável, que toma o conhecimento como dado, como fato e como conjunto de informações a serem repassadas às gerações mais jovens. O currículo já foi compreendido, a par de uma visão estritamente funcionalista do conhecimento, como conjunto de técnicas e recursos instrucionais, conferindo-lhe um caráter marcadamente instrumental e utilitarista, orientado por critérios economicistas de seleção dos saberes. A forma imóvel, pré-determinada de organização do saber escolar, ao lado de um modo pretensamente objetivista de lidar com esse saber, reflete o paradigma do esclarecimento burguês, que, aliado à idéia de progresso, converte a cultura em valor (de troca), o conhecimento em meio de adaptação e integração das crianças e dos jovens, e a formação humana, desprovida do caráter dialético de genuína formação cultural, torna-se uma formação que impede o indivíduo de reconhecer-se enquanto tal. A educação, que tem como característica ser uma função social permanente, deixa de se realizar como o processo pelo qual os indivíduos se apropriam das práticas e representações de seu grupo social e se torna parte dele, ao mesmo tempo em que se diferencia dele ao se tornar indivíduo.

As teorizações que se auto-intitulam como críticas em torno do currículo e das relações entre cultura e formação humana têm, muitas vezes, restringido-se a situar a escola como instância reprodutora das relações sociais e apontado o acesso ao "saber historicamente acumulado" como condição de superação das desigualdades sociais produzidas pela sociedade de classes. O acesso ao saber científico, no entanto, quando desprovido da condição de conferir significado às práticas culturais vivenciadas, permanece naquela forma desprovida de concreção e distante, portanto, de converter-se em genuína formação cultural. Evidencia-se, em algumas análises, seu caráter determinista, em outras, porém, nota-se a tentativa de superar os limites teóricos que até o momento têm impedido reflexões capazes de pensar as relações entre cultura, conhecimento, currículo, escola e formação humana.

Uma abordagem crítica do currículo, que privilegie a relação entre cultura, conhecimento e escola, requer o estudo das instâncias de formação cultural concretamente desenvolvidas, que têm constituído, simbólica e materi- 
almente, processos de formação gerados com base em uma cultura escolar racionalmente organizada e instituída mediante processos de dominação e controle. Para a compreensão do currículo como prática cultural, mostram-se necessários os estudos centrados na escola, em sua cultura, seus códigos e modos de organização, sem no entanto perder de vista a articulação do trabalho escolar ao contexto sociocultural e histórico-cultural.

A reflexão crítica em torno do sentido antropológico e histórico da cultura, bem como do conceito de cultura escolar e das relações entre cultura, conhecimento e escola, aponta para a compreensão de que, na escola, o currículo se converte em mediador na relação indivíduo-sociedade. A cultura, entendida como conjunto de significados por meio do qual se produz e reproduz uma certa ordem social ao instituir modos de vida material e imaterial (WILLIANS, 1992), confere a essa ordem social a condição de produtora de práticas e de representações por meio das quais se formam e se educam as gerações mais novas. Essa compreensão de cultura nos leva a pensar que toda prática escolar é cultura, mas uma forma particular de cultura, a cultura em uma "forma escolar", o que a caracteriza como "cultura escolar". O significado do termo cultura escolar pode ser o do modo como a escola se "institui", "organiza-se", "apropria-se" da cultura, faz determinadas "representações" dessa cultura e produz uma prática com vistas à formação humana. Essa prática é sempre mediada pelo conhecimento, traduzido em "cultura curricularizada". Historicamente, em nossa sociedade, essa cultura curricularizada tem se guiado por critérios instituídos pela razão burguesa, pela razão instrumental que converte o conhecimento em ideologia e aprisiona a consciência, impedindo a emancipação. A ciência se converte em religião e, tal como mostrara FREUD (1997), em O futuro de uma ilusão, a luta infindável entre indivíduo e civilização favorece a esta última, ainda que isso signifique o sacrifício do indivíduo.

A centralidade que o currículo tem adquirido contemporaneamente evidencia seu valor estratégico em se tratando da conservação e da conformação dos indivíduos e da própria sociedade. Em vários países acontecem reformas educacionais que têm como alvo principal os currículos escolares. Até mesmo a imposição de "currículos nacionais" tem se convertido em estratégias da política educacional. Como muitas das prescrições são semelhantes, quando não idênticas nos mais variados países, poder-se-ia pensar mesmo em um "currículo transnacional". Esse processo está associado aos fenômenos instituídos pela "globalização" e demais mudanças a ela associadas. No entanto, uma vez mais, o mercado (financeiro, de consumo e de trabalho) é quem dita as regras e enreda a educação escolar em uma retórica que busca vincular, de 
forma imediata, as mudanças na economia à "necessidade" de mudanças em outros aspectos da vida. Dentre os aspectos que "precisam se adequar", estariam as práticas escolares.

Essa centralidade dos currículos escolares confere às reformas educacionais o poder de definição não apenas de política educacional, mas de "política cultural". O modo de organização curricular proposto é elucidativo dessa lógica instrumental que mercantiliza a cultura, a escola e o conhecimento. A compreensão objetiva da prática social materializaria a posse de bens culturalmente aceitos e valorizados. Uma formação de tal modo conduzida levaria o indivíduo à capacidade de se inserir num mundo em permanentes transformações, contida a possibilidade da crítica mediante o medo de se tornar um a mais no rol dos excluídos. A razão instituída por meio do pensamento calculador reforça e reproduz, assim, os mecanismos de pseudoformação que limitam a formação cultural ao acesso às formas instrumentais, e portanto mecânicas, de explicar o mundo e a si próprio.

Observa-se no interior dos textos normativos, o emprego de termos anteriormente pouco utilizados e que, quando de seu uso, recorrer ao dicionário era suficiente. Uma das características conferidas aos conceitos utilizados é a da sua "operacionalidade". Para esse fim, propõe-se, por exemplo, como princípios de organização do trabalho escolar, a ética, a política e a estética. ${ }^{2}$

Em que sentido estariam sendo propostos para a organização curricular os princípios da estética, da política e da ética? Estes são definidos e justificados em função de se pretender promover uma adaptação da formação humana às exigências da sociedade contemporânea, entendida como uma sociedade tecnológica que, ao alterar o modo de organização do trabalho, altera as relações sociais. Desse modo, estaria se justificando o fato de que toda a formação humana, inclusive a que não visa à formação profissional, deve tomar o trabalho como princípio organizador do trabalho educacional, escolar, e curricular. Esta questão será retomada à frente.

No mesmo sentido, instrumental e operacional, propõe-se tomar a estética como referência para a organização curricular das escolas de Ensino Fundamental e Médio. Teria, ainda, a finalidade de promover uma nova "sensibilidade", determinada pelas mudanças na sociedade pós-industrial:

2 Para efeitos da análise aqui empreendida, toma-se as Resoluções e Pareceres da Câmara de Educação Básica do Conselho Nacional de Educação, que instituem as Diretrizes Curriculares Nacionais para o Ensino Fundamental e Médio. 
Como expressão do tempo contemporâneo, a estética da sensibilidade vem substituir a da repetição e padronização, hegemônica na era das revoluções industriais. Ela estimula a criatividade, o espírito inventivo, a curiosidade pelo inusitado, a afetividade, para facilitar a constituição de identidades capazes de suportar a inquietação, conviver com o incerto, o imprevisível e o diferente. (BRASIL, 1998)

"Estética da sensibilidade". No plano dos significados etimológicos e semânticos é possível identificar nessa proposição um problema inicial: toda estética é sempre relativa à sensibilidade: à sensação ou à capacidade de sentir. Desse modo, não faz sentido dizer que o que diferencia a sociedade do presente da sociedade industrial assentada na estética da repetição e da padronização é a emergência de uma estética da sensibilidade. (SAVIANI, 1998, p. 1) Se, de algum modo essas sociedades se diferenciam, provavelmente isso é devido também à estética que produzem e/ou reproduzem, no entanto, também a sociedade da padronização e da repetição, quando se trata de estética, comporta uma estética da sensibilidade. Chama a atenção, por seu cinismo brutal, a afirmação de que devemos nos ocupar de formar alguém capaz de suportar a inquietação, conviver com o incerto, o imprevisível e o diferente. De fato, em um mundo que não oferece sequer garantias mínimas de sobrevivência, só é possível pensar em uma educação voltada para a aceitação do inesperado e pela convivência com as incertezas. Porém, assumir isso como "dado" e como inevitável em um momento em que se está se propondo uma política de formação humana é, no mínimo, valer-se daquela frieza necessária à consolidação de normas que instituem a barbárie ou algo próximo à ela.

A estética da sensibilidade realiza um esforço permanente para devolver ao âmbito do trabalho e da produção a criação e a beleza daí banidos pela moralidade industrial taylorista. Por essa razão, procura não limitar o lúdico a espaços e tempos exclusivos, mas integrar diversão, alegria e senso de humor a dimensões de vida muitas vezes consideradas afetivamente austeras como a escola, o trabalho, os deveres, a rotina cotidiana. Mas a estética da sensibilidade quer também educar pessoas que saibam transformar o uso do tempo livre num exercício produtivo porque criador. E que aprendam a fazer do prazer, do entretenimento, da sexualidade, um exercício de liberdade responsável. (BRASIL, 1998) 
Conferir ao trabalho essa carga de sofrimento humano não é exatamente o que se pode chamar de uma idéia inovadora. No entanto, propor que a diversão, alegria e senso de humor ocupem também os espaços de trabalho, dentre outros, e que isto depende de uma formação voltada para essa finalidade, é de fato acreditar na capacidade da palavra de substituir a própria realidade ou, então, essa proposição expressa o máximo da racionalidade instrumental (e cínica): a sensibilidade e o respeito às diferenças culturais constitui o elo que significa ao mesmo tempo ameaça e resignação. É preciso aceitar para ser aceito!

Também a política tomada como princípio explicita o caráter funcional que se quer conferir às práticas curriculares. Essa funcionalidade produz 0 que poderíamos chamar de uma "escola administrada", compreendida como uma educação escolar passível de ser plenamente controlada.

A política da igualdade incorpora a igualdade formal, conquista do período de constituição dos grandes estados nacionais. Seu ponto de partida é o reconhecimento dos direitos humanos e o exercício dos direitos e deveres da cidadania, como fundamento da preparação do educando para a vida civil.

Para essa sociedade, a política da igualdade vai se expressar também na busca da equidade no acesso à educação, ao emprego, à saúde, ao meio ambiente saudável, e outros benefícios sociais e no combate a toda as formas de preconceito e discriminação por motivo de raça, sexo, religião, cultura, condição econômica, aparência ou condição física. (BRASIL, 1998)

A política tomada como princípio da organização curricular já evidencia uma intencionalidade fundada na razão instrumental. De outra forma não seria possível prescrever como fundamento da formação humana aquilo que é próprio da sociedade em que esta formação se realiza. Tomados em sentidos idênticos, os termos política da igualdade e busca da equidade explicitam uma contradição. Igualdade e equidade não se eqüivalem, nem mesmo se complementam, ao contrário, se excluem: 
O texto trata o conceito de igualdade de forma intercambiável com o de equidade. Entretanto, equidade, registram os dicionários, é "a disposição de reconhecer igualmente o direito de cada um" (sentido 1), portanto, implica o reconhecimento e legitimação das desigualdades, conduzindo ao tratamento igual dos desiguais. Isso fica mais claro ao se considerar o sentido 2: "conjunto de princípios imutáveis de justiça que induzem o juiz a um critério de moderação e de igualdade, ainda que em detrimento do direito objetivo". (Aurélio, s/d: p. 544). Ora, o direito objetivo não é outra coisa senão o "conjunto de normas de caráter obrigatório impostas pelo estado, e que compreende o direito escrito e o consuetudinário"(Ibidem: p. 479). Por fim o significado de equidade resulta cristalino ao se levar em conta o sentido 3: "sentimento de justiça avesso a um critério de julgamento ou tratamento rigoroso e estritamente legal: (Ibidem: p. 544). Em contrapartida, igualdade, também segundo os dicionários, significa "qualidade ou estado de igual; paridade; uniformidade; identidade". E, em termos éticos: "relação entre os indivíduos em virtude da qual todos eles são portadores dos mesmos direitos fundamentais que provêm da humanidade e definem a dignidade da pessoa humana.”(Ibidem: p. 740). Portanto, os dois conceitos são incompatíveis. (SAVIANI, 1998, p. 2)

A mesma funcionalidade conferida aos sentidos da estética e da política estão presentes na ética levada à condição de princípio da organização curricular do Ensino Médio. A ética é tomada como a possibilidade de manter o ideal humanista que subjugaria o caráter totalitário da sociedade industrial. Teria por função instituir uma formação desprovida da finalidade de formar pessoas honestas para considerar a possibilidade de formação de identidades. O que esconde esse jogo de palavras, senão a intenção de conferir a aparência de inovação a algo que permanece, mas que necessita redimensionar certos significados com o fim de manter em novas bases a mesma racionalidade?

A ética da identidade substitui a moralidade dos valores abstratos da era industrialista e busca a finalidade ambiciosa de reconciliar no coração humano aquilo que o dividiu desde os primórdios da idade moderna: o mundo da moral e o mundo da matéria, o privado e o público, enfim a contradição expressa pela divisão entre a "igreja" e o "estado". Essa ética se constitui a partir da estética e da política e não por negação delas. Seu ideal é o humanismo de um tempo de transição. 
Como princípio educativo, a ética só é eficaz quando desiste de formar pessoas "honestas", "caridosas" ou "leais" e reconhece que a educação é um processo de construção de identidades. Educar sob inspiração da ética não é transmitir valores morais mas criar as condições para que as identidades se constituam pelo desenvolvimento da sensibilidade e pelo reconhecimento do direito à igualdade a fim de que orientem suas condutas por valores que respondam às exigências do seu tempo. (BRASIL, 1998)

O sentido em que é tomado o termo "ética" é o mais claro exemplo de como a locução política se comporta como ideologia, no sentido que MARCUSE (1982) confere a essa palavra. A racionalidade tecnológica é transposta, pela mediação da palavra, à racionalidade política. O universo da palavra é moldado, assim, por um "projeto" de sociedade, que a estabiliza "e contém o progresso técnico dentro da estrutura de dominação." (MARCUSE, 1982, p. 19)

O exposto nos remete mais uma vez a ADORNO (1995a): especial atenção precisa ser dada à linguagem utilizada nas proposições da reforma educacional em curso, uma vez que a "reflexão acerca da linguagem constitui o parâmetro original de qualquer reflexão filosófica." (ADORNO, 1995a) Por meio das palavras institui-se aquele mecanismo que MARCUSE (1982) chamou de $o$ fechamento do universo da locução: ao invés de significados, a locução totalitária própria da sociedade industrial reduz o conceito a uma caráter operacional e funcional ao qual só é possível uma única interpretação. As palavras são desprovidas de concreção, o que permite, por meio delas, instituir-se uma racionalidade política mediante a transposição, para todas as dimensões da vida humana, de uma racionalidade instrumental e tecnológica.

No interior das prescrições da reforma curricular, a própria linguagem é tomada em seu caráter funcional cujo propósito é de viabilizar o acesso aos conhecimentos produzidos pela sociedade tecnológica. A língua é compreendida não como condição de formalização do pensamento, que conduziria à capacidade de reflexão e de crítica, mas como a função mental pela qual o homem se comunica e, além disso, "se torna os suportes decisivos para os conhecimentos tecnológicos a serem dominados.” (BRASIL, 1998)

É possível identificar no Parecer citado uma "linguagem cifrada". O teor de suas palavras permite, quando submetido à crítica que lhe confere a concreção de que está desprovido, perceber o quanto o que está dito esconde o não dito e vice-versa. 
Todas essas proposições convertem os significados em significado operacional e têm como objetivo materializar uma formação humana também funcional. As mudanças na sociedade industrial precisam, para ganhar legitimidade, se orientar por novas concepções, pois aquelas que até o momento lhe deram legitimidade, tornaram-se por demais significativas para permanecerem. (MARCUSE, 1982, p. 25) É preciso encontrar novas palavras, porém que expressem a mesma linguagem unidimensional. Manifestase aí uma das principais características da razão instrumental: seu caráter irracional que leva à "transformação do resíduo em necessidade e a destruição em construção.” (MARCUSE, 1982, p. 29)

É dada particular ênfase ao trabalho como princípio organizador do currículo para as escolas dirigidas aos jovens. Isso tem como justificativa uma concepção da vida humana que tem na atividade do trabalho seu maior fundamento. O trabalho, assim considerado, tornar-se-ia imprescindível para a compreensão dos fundamentos científico-tecnológicos dos processos produtivos, base sobre a qual deve se assentar toda a formação humana. Justificamse as "inovações" por meio das mudanças que vêm ocorrendo no "mundo do trabalho". Novas tecnologias - assentadas no emprego da microeletrônica -, bem como novas estratégias de gestão e organização do trabalho inspiradas no Japão, estariam pondo como desafio para o setor produtivo demandas específicas de formação para o trabalho. Tais exigências de formação do trabalhador, têm recorrido ao chamado "modelo de competências" para traçar o perfil desse "novo" trabalhador. Assim como o conceito de competências, os demais termos, conceitos e proposições tomam, claramente, como foco restrito o "mercado de trabalho". A "sociedade tecnológica do futuro" estaria exigindo uma formação de determinado tipo. Evidenciam-se, deste modo, os propósitos de adaptação das práticas escolares às mudanças econômicas e às inter-relações entre estas e as decisões no âmbito da política educacional.

Nota-se a ausência de crítica, seja por parte dos que aderiram à idéia da inevitabilidade das mudanças econômicas, seja por parte dos que fazem a crítica a tais mudanças devido ao seu caráter excludente, ambos justificam a necessidade das mudanças curriculares com base nas transformações do mercado. Mais do que nunca, o conhecimento tornou-se mercadoria que confere valor a uma outra mercadoria: a educação escolar. O caráter instrumental, objetivo e mercantil da formação pode ser identificado por meio da tentativa de operacionalização dos mais variados conceitos. Isso corresponde à implementação calculada dos resultados esperados da escolarização. É a explicitação sem máscaras da racionalização das categorias formativas. O caráter instrumental da educação se mostra no imperativo de formação 
pretensamente capaz de atender às mudanças na produção e no trabalho. Isso evidencia o modo como a dominação e o controle se colocam no quadro da atual sociedade tecnológica. Ao fetichismo tecnológico sucumbem não apenas os indivíduos a ele propensos. As tendências em torno da formação humana administrada, a educação pela organização escolar fundamentada no domínio da técnica e da tecnologia, reportam a formação escolar à condição de mercadoria, uma vez assumido o mercado como paradigma. A formação para o progresso se mantém como antiformação.

A implementação das mudanças fica, no entanto, a cargo das escolas, e o modo como estas dão materialidade às propostas e redimensionam seus significados nos oferece a sensação de que não somos meros fantoches. A formação da classe de professores, anos a fio precarizada, porém, nos torna reféns da razão instrumental e confirma que a civilização, contraditoriamente, produz o anticivilizatório. A autoridade instituída na e pela escola assume o papel da produção da consciência coisificada. A linguagem, transfigurada pela ausência de reflexão e crítica, interpõe-se entre o indivíduo e o conhecimento. A possibilidade de formação cultural capaz de gerar a capacidade de reflexão e crítica é agora administrada e controlada por critérios objetivamente mensuráveis que separam os competentes dos incompetentes. $\mathrm{O}$ conformismo coletivizado estabelece o clima necessário ao controle e à dominação, quando o poder público opera de modo a conseguir com que os educadores internalizem o controle, pelo medo, sobre si próprios. Ainda assim, "os professores não reproduzem simplesmente de um modo receptivo algo já estabelecido." (ADORNO, 1995b)

A condição contraditória da realidade impede que se convertam todos os elementos de formação em vetores de animalidade e embrutecimento. $\mathrm{O}$ currículo e seus elementos de cultura, cotidianamente mediados pela prática escolar é constituídor de subjetividades e ainda que a possibilidade de emancipação seja restrita, a possibilidade de uma formação capaz de se escandalizar com a violência e restringi-la contribui para a contenção da barbárie. Isso, porém, nos parece insuficiente.

A compreensão das causas que contemporaneamente têm mantido e confinado a educação escolar à condição de produtora de pseudoformação é objeto valioso de teorização e crítica e contribui especialmente para a apreensão das inter-relações entre cultura, conhecimento e escola. A reflexão sobre os mais variados aspectos da lógica imposta à organização escolar permite visualizar a que vêm as propostas de mudanças e denunciá-las como manifestação de uma autoridade que deseja a barbárie. A crítica se torna imprescindível: aquele que pensa, impõe resistência. 


\section{REFERÊNCIAS}

ADORNO, T. W. Educação após Auschwitz. In: ADORNO, T. W. Palavras e sinais: modelos críticos 2. Tradução de Maria Helena Ruschel. Petrópolis: Vozes, 1995.

A filosofia e os professores. In: Educação e emancipação. Tradução de Wolfganf Leo Maar. Rio de Janeiro: Paz e Terra, 1995a . Tabus acerca do magistério. In: . Educação e emancipação. Tradução de Wolfganf Leo Maar. Rio de Janeiro: Paz e Terra, 1995b.

- Teoria da Semicultura. Educação e Sociedade, ano 17, n. 56, dez. 1996.

.; HORKHEIMER, M. O conceito de esclarecimento. In: . Dialética do esclarecimento. Tradução de Guido Antonio de Almeida. Rio de Janeiro: Zahar, 1985.

BRASIL. Parecer 04/98 e Parecer 15/98 - Diretrizes Curriculares Nacionais para o Ensino Fundamental e Médio. Câmara de Educação Básica/Conselho Nacional de Educação. Brasília, 1998.

DALE, R. A educação e o estado capitalista: contribuições e contradições. Educação e Realidade, Porto Alegre, n. 13, p. 17-37, 1988.

FREUD, S. O futuro de uma ilusão. Tradução de José Octávio de Aguiar Abreu. Rio de janeiro: Imago, 1997.

MARCUSE, H. A ideologia da sociedade industrial. O homem unidimensional. Tradução de Giasone Rebuá. Rio de Janeiro: Zahar, 1982.

SAVIANI, D. Comentários sobre o Parecer Diretrizes Curriculares Nacionais para o Ensino Médio, de Guiomar Namo de Mello. Comentários apresentados pelo autor, representando a Unicamp, na audiência pública convocada pela Câmara de Educação Básica do Conselho Nacional de Educação, organizada em conjunto com o Conselho Estadual de Educação de São Paulo e realizada no dia 18 de maio de 1998, no Auditório "Fernando de Azevedo" na sede da Secretaria de Educação do Estado de São Paulo. (Mimeog).

WILLIAMS, R. Cultura. Tradução: Lólio Lourenço de Oliveira. Rio de Janeiro: Paz e Terra, 1992. 